\title{
Multiple paradoxical embolisms in patient with patent foramen ovale - case report
}

\section{Matias Trbušić "*, Vesna Degoricija', Krešimir Štambuk², Jelena Dumančić', Ivo Darko Gabrić', Danijel Planinc'}

'University Hospital Centre "Sestre milosrdnice", Zagreb, Croatia

${ }^{2}$ Magdalena Clinic for Cardiovascular Medicine, Krapinske Toplice, Croatia
RECEIVED:

January 17, 2016

ACCEPTED:

February 20, 2016

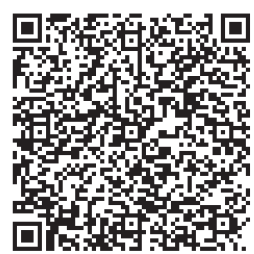

KEYWORDS: patent foramen ovale, paradoxical embolism, percutaneous patent foramen ovale closure.

CITATION: Cardiol Croat. 2016;11(3-4):139. | DOI: http://dx.doi.org/10.15836/ccar2016.139

*ADDRESS FOR CORRESPONDENCE: Matias Trbušić, Klinički bolnički centar Sestre milosrdnice, Vinogradska 29, HR-10000 Zagreb, Croatia. / Phone: +385-99-378-7064 / E-mail: matias.trbusic@gmail.com

ORCID: Matias Trbušić, http://orcid.org/0000-0001-9428-454X • Vesna Degoricija, http://orcid.org/0000-0001-6226-4018 Krešimir Štambuk, http://orcid.org/0000-0002-9107-6187 • Jelena Dumančić, http://orcid.org/0000-0002-1635-1521 Ivo Darko Gabrić, http://orcid.org/0000-0003-4719-4634 • Danijel Planinc, http://orcid.org/0000-0002-1799-8554 IIIIIIIIIIIIIIIIIIIIIIIIIIIIIIIIIIIIIIIIIIIIIIIIIIIIIIIIIIIIIIIIIIIIIIIIIIIIIIIIIIIIIIIIIIIIIIIIIIIIIIIII

The diagnosis of paradoxical thromboembolism (PT) is based on the triad: venous thromboembolism, systemic arterial embolism in the absence of intracardiac thrombus, and intracardiac defect, usually a patent foramen ovale (PFO). ${ }^{1}$

We present a case of 54-year-old patient who complained of chest pain and shortness of breath. MDCT angiography showed massive pulmonary embolism (PE) and infarction of left kidney while Doppler showed deep vein thrombosis (DVT) of the right popliteal vein. Due to patients' high weight (BMI 46.6 $\mathrm{kg} / \mathrm{m}^{2}$ ), therapy with unfractionated heparin was started. Transthoracic echocardiography showed pulmonary hypertension and no intracardiac thrombus or tumors. During the next 24 hours the patient developed thromboembolic occlusion of right axillary artery and the urgent embolectomy was done. After 48 hours, the patient reported severe pain in the right lumbar region and right leg. MDCT angiography revealed right renal artery and the Doppler right femoral artery thromboembolism (second embolectomy was performed). Contrast enhanced transesophageal echocardiography (TEE) revealed tunnel-type PFO and spontaneous right to left flow. Because of repetitive PT despite optimal heparin therapy a temporary vena cava filter (VCF) was placed. The patient was further with no signs of re-embolism (discharged with warfarin). It was proven that the he has positive PAI-1 gene 4G/4G mutation. Two and a half months after the first hospitalization the temporary vena cava filter was removed. Due to the genetic thrombophilia, large PFO and spontaneous right-left flow, a decision was made to perform a percutaneous PFO closure with Amplatzer occluder device.

In conclusion: if the arterial thromboembolism occurs in the settings of DVT and PE contrast enhanced TEE must be done as soon as possible owing to high sensitivity and specificity in detection of PFO and other intracardial shunts and masses. ${ }^{2}$ This seems to be especially important if the patient has proven thrombophilia. Temporary VCF is an unavoidable option if the patient has repetitive PE or arterial thromboembolism. Percutaneous closure of PFO (together with lifelong anticoagulation therapy) was the definite treatment in our patient despite the unfavorable results in studies for secondary prevention of cryptogenic embolism. ${ }^{3}$

LITERATURE IIIIIIIIIIIIIIIIIIIIIIIIIIIIIIIIIIIIIIIIIIIIIIIIIIIIIIIIIIIIIIIIIIIIIIIIIIIIIIIIIIIIIIIIIIIIIIIIIIIIIII

1. Johnson BI. Paradoxical embolism. J Clin Pathol. 1951;4:316-32. DoI: http://dx.doi.org/10.1136/jcp.4.3.316

2. Chen WJ, Kuan P, Lien WP, Lin FY. Detection of patent foramen ovale by contrast transesophageal echocardiography. Chest. 1992;101(6):1515-20. DOI: http://dx.doi.org/10.1378/chest.101.6.1515

3. Meier B, Kalesan B, Mattle HP, Khattab AA, Hildick-Smith D, Dudek D, et al; PC Trial Investigators. Percutaneous closure of patent foramen ovale in cryptogenic embolism. N Engl J Med. 2013;368(12):1083-91. DOI: http://dx.doi.org/10.1056/NEJMoa1211716 